\title{
Becoming a leader: the challenge of modesty for women
}

\author{
Marie-Hélène Budworth \\ School of Administrative Studies, York University, Toronto, Canada, and \\ Sara L. Mann \\ Department of Business, University of Guelph, Guelph, Canada
}

\begin{abstract}
Purpose - While the number of women in managerial positions has been increasing, the gender composition of top management teams is skewed. There are barriers and obstacles in place that limit the movement of women into leadership roles. The purpose of this paper is to examine the relationship between modesty and access to leadership. Specifically, tendencies toward modesty and lack of self-promotion are hypothesized to perpetuate the lack of female involvement in top management positions.

Design/methodology/approach - The literature on modesty and self-promotion is reviewed. The findings are discussed in terms of the persistent challenges faced by women with regard to their ability to enter senior levels of management.

Findings - The overall message of the paper is that behaviours that are successful for males in the workplace are not successful for females. The good news is that women do not need to adopt male ways of being in order to succeed. A limitation is that the paper is largely "uni-cultural", as the research referenced is primarily that undertaken in a North American context. Self-promotion and modesty may be conceptualized differently in other contexts.
\end{abstract}

Originality/value - The paper is one of the first to focus on modesty, an important gendered individual difference, to explain persistent workplace inequalities.

Keywords Women, Gender, Leadership

Paper type Conceptual paper

\section{Introduction}

Researchers and the popular press alike have lauded women as having the skills necessary for leadership in the twenty-first century (Eagly et al., 2003; Sinclair, 1995). At the same time, women often come in second to men in competitions to attain leadership positions (Eagly, 2007). In 2006, women comprised only 26 percent of senior leaders, compared with 37 percent of leaders at other levels (Statistics Canada, 2006). Women hold only 7.9 percent of the highest corporate officer titles and make up only 5.2 percent of the top earners in Fortune 500 companies (Catalyst, 2002).

The discrepancy between the observed aptitude of women for leadership roles and the current composition of top management teams is inconsistent. This inconsistency can be explained in terms of selection for leadership (Eagly, 2007). There are barriers and obstacles in place that limit the movement of women into leadership roles. The current paper is concerned with addressing the issue of access to senior level leadership

This research was funded in part by a Social Sciences and Humanities Research Grant to the first author. 
positions. In this sense, the focus is on becoming a manager in today's current cultural climate.

There has been a large volume of academic research that has provided theoretical and empirical explanations for the persistent discrepancies in the propensities of men to move into leadership positions in greater numbers than women. To a large extent, that literature has focused on the contextual factors that continue to support the progression of males to top-level positions. For example, researchers have been preoccupied with the glass ceiling as well as organizational policies and practices that limit access for women to the inner circles of organizational leadership (Eagly and Carli, 2007). These structural level issues are important and represent immense barriers. Awareness of these macro-level structures is important for understanding the root causes of a problem, however, can appear insurmountable in the eyes of the individual attempting to have an impact on their personal circumstances (Bandura, 1986).

Theorists have argued that it can be powerful to consider individual level interventions that teach people how to persist when faced with seemingly insurmountable obstacles (Yanar et al., 2008). For example, Yanar et al. (2008) trained women in Turkey in a technique that increases confidence in reemployment in order to overcome overt employment discrimination practices in Istanbul. They found that training was able to increase the ability of women to find employment even though the laws, policies, and practices of the local employers remained unchanged.

The intention of approaches that target the individual is not to problematize the individual or encourage women to behave in ways that are inconsistent with their social context. Instead, addressing bottom up approaches arms individuals with the skills necessary to overcome societal level obstacles. The aim is to assist women in gaining entry into leadership positions so they can alter our implicit assumptions about who is a "good leader." While approaches that address the root of the problem are ideal, these types of approaches have proven slow and difficult to implement. This paper discusses an individual level approach that can be implemented today in the climate and culture we find ourselves in currently.

"Becoming" a leader is distinct from "being" a leader. The extant literature has invested a great deal of effort into understanding the skills necessary for effective leadership (Ayman, 2004). Less focus has been given to the skills required to become a leader. Owing to the apparent discrepancy between leadership potential and leadership opportunities for women, more work needs to be done to assist women in gaining access to leadership opportunities. This paper will address the question of whether there are gender differences in behaviours that predict entry into leadership positions. In particular, the gender difference of values toward modesty and self-promotion is examined.

\section{Gender differences in leadership}

Theorists and researchers have avoided discussions of gender-driven individual difference factors that contribute to the gender divide. Many researchers were thought to be "profoundly uncomfortable" with this area of study (Beall et al., 2004, p. 4). Academics have often maintained that female and male leaders do not differ (Bartol and Martin, 1986). The implications of this belief are that males and females need to be prepared and developed for leadership roles in the same way. 
Developing male and female leaders using the same methods ignores any legitimate differences that exist between men and women based on life experience and gender socialization. It assumes that men and women will have similar opportunities and experiences. It also assumes that men and women will be perceived in the same way for exhibiting similar behaviours; an idea that is not supported for a range of activities including networking (Forret and Dougherty, 2004), the expression of anger (Brescoll, 2007), and entrepreneurship (Heilman and Chen, 2005). Research is needed to understand how gender differences affect leadership emergence, selection, and development in order to assist women in becoming executive managers and breaking into top levels of management.

More recently, researchers have begun to investigate gender differences with a focus on the contextual patterns that make the differences between genders important. The advancement in this area of study is significant as it continues to enhance our understanding of the differing experiences of men and women in the workplace. It is these differences that are leading us toward a better understanding of the behaviours that propagate support for male versus female leadership.

Eagly et al. (2003), published a meta-analysis wherein they examined the leadership styles of males and females. They found that female leaders were more likely to engage in transformational leadership behaviours: a form of leadership found to be more effective compared to other leadership styles. Still, female leaders are evaluated less favourably than males (Eagly and Karau, 2002), especially in contexts that are male dominated and strongly hierarchical (Eagly et al., 2003). Findings that elucidate effective leadership and management strategies for males versus females are instructive for our understanding of leadership development. Researchers and practitioners are gaining insights into how to change the landscape of top-level management. It is not sufficient to investigate leadership effectiveness in its current form and then to use current models of leadership to develop young female managers (Sinclair, 1997). As researchers, we can add value by identifying the behaviours that support and prohibit effective leadership and career progression for females and use this understanding to develop female managers.

A phenomenon widely investigated within the social psychology literature is directly relevant to our understanding of behaviours that have a direct effect on career progression, namely the feminine modesty effect. This paper explores the application of this phenomenon to the career experiences of women and discusses the implications of modesty for achievement and reward in a work context.

\section{Feminine modesty}

Modesty implies that the individual downplays the self and employs a strategy of highlighting the achievements or contributions of others (Wade, 2001). Similarly, modest people do not ask for rewards for themselves, but they may ask for rewards for others. A prevalent finding in social psychology research is that women under-represent their accomplishments to others whereas men consistently self-promote their successes (Berg et al., 1981). Because women have been socialized to believe that they will experience more positive outcomes regarding their accomplishments when they are seen by others as non-competitive, they downplay their accomplishments in the presence of others to avoid being judged unfeminine (Daubman and Sigall, 1997; Gould and Slone, 1982; Rudman and Glick, 1999). In 
contrast, men consistently self-promote their successes, in order to present a successful self-image to others (Gould and Slone, 1982). This tendency for women to under represent their accomplishments to others has been labeled the "feminine modesty" effect (Cialdini and De Nicholas, 1989).

Daubman and Sigall (1997) found that one reason why women did not make immodest self-disclosures of their achievement to a low-achieving peer is because they believed that the other person would like them less than if they made modest self-disclosures of their achievement. Women under-represent their performance, relative to men, in interactions with both males and females. This research demonstrates that men and women make different inferences about how disclosures of their own performance affect others' feelings and others' attraction toward them. Women who "bragged" about their performance on a task inferred that another woman liked them less than women who disclosed about their performance in a more modest way. This occurred whether the peer had performed as well as the participant or had performed considerably worse. In contrast, men's judgments of how much a woman liked them were either not affected by whether they disclosed modestly or immodestly or they judged that the woman liked them more when they had "bragged". Neither men's nor women's judgments of how much a man liked them were affected by whether they were modest or bragged.

The modesty phenomenon occurs among students in university settings (Daubman and Sigall, 1997; Gould and Slone, 1982) as well as career settings (Giacalone and Riordan, 1990; Tannen, 1994). For instance, Tannen (1994) found, in her observation of conversational styles of women and men in the workplace, that women make fewer claims of success than men and consequently receive less recognition for their work.

Modesty is hypothesized to have debilitating effects on the careers of women (Wade, 2001). Based on the common axiom of performance appraisals, work that is not recognized is not compensated. Giacalone and Riordan (1990) stated that if women want to get their work recognized, they should self-present following success to ensure that they receive the recognition and credit deserved, especially if the quality or difficulty of the accomplishment is not clearly understood.

Budworth and Mann (2007) found that while men are financially rewarded for holding modest values, women are economically penalized. In a study of unionized manufacturing employees, it was found that women who score low on modesty earn a larger income than those who score high while men who score high to moderate in modesty earn a larger income than those who score low. In this case, it appears as though males and females are rewarded differently for the same behaviors in the workplace. This is likely due to behavioural differences in how modesty is displayed by men versus women. Women who self-promote likely do so in a way consistent with gender expectations. They present their accomplishments factually without appearing boastful or arrogant. In contrast, Budworth and Mann (2007) proposed that men with high modesty self-promote in a similar fashion to women with low modesty. Conversely, men low in modesty may be perceived as boastful or aggressive.

\section{Gender stereotypes}

Differences in self-presentation between men and women are due to both descriptive and prescriptive gender stereotypes; gender stereotypes denote differences in how women and men "actually are" and denote norms about how men and women should 
behave or "should be" (Eagly and Karau, 2002; Rudman and Glick, 2001). Moreover, the descriptive and prescriptive stereotypes for men and women overlap in that the behavior that is prescribed for each gender is positively related to the attributes that are valued. Women are supposed to be socially sensitive. Kindness, thoughtfulness, sensitivity and other stereotypically "feminine" behaviours that demonstrate a concern for others are referred to as communal. Men, on the other hand, are supposed to behave in a self-assertive fashion. Behaviours such as competence and dominance are termed agentic behaviours and are stereotypically expected from men. Social role theory explains the emergence of these characteristics.

According to social role theory, behavioral gender differences are caused by socialization where at a young age, males are encouraged and rewarded for being outgoing, and achievement oriented. Conversely, females, are taught to be emotionally oriented, and reserved in their interactions with others (e.g. Wade, 2001). When either gender behaves in a manner inconsistent with these prescriptions they are met with disapproval and penalties (Eagly and Karau, 2002).

Research has demonstrated that when women enact agentic behaviors they are perceived as competent (Rudman, 1998), but they are seen to be less socially skilled and less likable as compared to an identically presented male (Rudman and Glick, 2001). Similarly, communal men are viewed as less competent and hirable compared with agentic men (Rudman, 1998; Rudman and Glick, 1999, 2001). These effects have been labeled "backlash" and called a catch-22. Backlash is defined as social and economic sanctions for counter-stereotypical behaviour (Rudman, 1998). They represent a double-edged sword where it appears as though women can be penalized economically and professionally for behaving in ways consistent with successful men. At the same time, women are less likely to succeed and be viewed as competent if they behave in a strictly communal fashion. On the surface it appears as though women's tendency toward modesty is well founded. Is there a potential risk to likeability, an important predictor of selection and advancement, if women self-promote? Fortunately, it is not as dire as it appears.

Rudman and Glick (2001) found a subset of agentic traits that elicit backlash. Specifically, women who are socially dominant (e.g. competitive, aggressive) are disliked because this quality conflicts with attributes of feminine niceness. Applicants that are viewed as socially deficient, and dislikeable suffer hiring discrimination (Rudman, 1998; Rudman and Glick, 1999, 2001). Self-promotion enhances the attribution of competence (Kacmar et al., 2004), and competence is not discriminated against in terms of backlash (Rudman and Glick, 2001). Collectively, these results suggest that women are better off, self-promoting than acting modestly in situations where competency is desirable. Rudman and Glick (1999) stated that regardless of sex, "nice" applicants are rated quite poorly and lose out to more agentic applicants for either a feminine- or masculine-type job.

\section{Implications of modesty}

Arguably, there are important consequences of behaving modestly. Modesty is the converse of self-promotion, a set of impression management behaviours that have been linked to a variety of career outcomes including successful performance in a job interview (Kacmar et al., 1992) and effective networking (Forret and Dougherty, 2004). Although the relationship between self-promotion and performance appraisals have 
not been empirically tested, one can predict that women's tendency to be modest in the reporting of their achievements influences the perceptions of their accomplishments in the workplace and the subsequent reward and promotion.

Research on performance appraisals has shown that men are usually evaluated as more effective than women (Eagly et al., 1995). Research has also shown that after controlling for age, education, tenure, salary grade, functional area, and satisfaction with support for one's career, gender is related to the appraisals of one's promotion potential in that females are rated lower than males (Landau, 1995). Perceptions are that men possess the leadership qualities and motivation needed for effective performance, while women possess feminine attitudes that hinder effective performance (Boldry et al., 2001). Future research should investigate the relationship between performance appraisals of women and their tendency toward modesty. Again, work that is not recognized is not rewarded. Women continue to believe that hard work alone will result in career reward and often fail to promote their personal successes and interests to those in control of the resources (Tannen, 1994)

On the surface, the practical implications of the modesty phenomenon are that women inherently behave in ways that are counterproductive to career success. The modest behaviours that women exhibit in order to fit into their gender roles may result in likeability, but at a cost to access to leadership positions and economic reward. From this line of research, it would be logical to conclude that women need to make a choice between likeability and success in terms of career progression and remuneration. As a consequence, women are faced with a double-edged sword when it comes to entry into top-level management. However, there is literature to suggest that self-promotion

behaviours are rewarded for women. Self-promotion enhances perceptions of competency (Rudman and Glick, 2001). Women tend to avoid these behaviours because they believe they will be penalized for acting in an agentic fashion. There are agentic behaviours that are not tolerated when displayed by women in the workplace including dominance and aggression, but not self-promotion (Rudman and Glick, 2001). Interestingly, dominance and aggression are not appreciated when displayed in males either (Eagly et al., 2003), but they are tolerated to a greater degree. Research indicates that males in senior executive roles are most effective if they are charismatic, communicate effectively, and focused on the needs of their followers (Eagly et al., 2003); tendencies that are largely communal or "feminine" in orientation.

The fact that men continue to rise to leadership positions in both "masculine" and "feminine" industries implies that access to leadership is problematic across settings. However, there may be different implications for behaving modestly in different settings. These differences should be examined in future research. Similarly, most of the extant research has been conducted in a climate where men are the decision makers in terms of who will enter the ranks of leadership. As more women enter into leadership positions and became part of the team that selects and promotes future leaders, the implications of research on modesty and self-promotion may change.

\section{Becoming a leader}

Researchers once avoided a discussion of the differences between males and females. A potential fear may have been that identifying behaviours and strategies that make males successful would have resulted in "fix the women" solutions. The discomfort may have been around the idea that once differences between genders were revealed 
interventions would have been designed to teach women to behave in ways consistent with successful men. At the present time, it is naïve to assume that men and women will be rewarded in the same way for the same behaviours.

Current models of leadership and leadership development cannot be applied to males and females in the same way. The research in organizational settings should focus on understanding the ways of "becoming" and "being" for males and females in order to identify strategies for each gender in terms of understanding what it means to be a successful manager from each perspective. This knowledge has the potential to arm female managers with the skills necessary to "become" leaders by gaining access to top level management positions.

As noted in the introduction to this paper, there are more females in managerial positions today than in previous decades. While the number of women in executive leadership roles is still small, 7.9 percent in 2002 (Catalyst, 2002), there are a number of prominent female leadership examples available. These include Cathleen Black, president of Hearst Magazine, Meg Whitman, president of eBay, Shelly Lazarus, CEO of Ogilvy and Mather, and Anne Mulcahy, CEO of Xerox. The emergence of women into these roles allows us as researchers to investigate in field settings how female leaders are perceived by their followers. There is an opportunity at the present time to gain a deeper understanding of female leadership than was available in previous decades. Our research into understanding the differences between female and male leadership effectiveness can help to inform how we can continue to develop leaders. In the long run, knowledge about successful strategies for leadership can help us to design appropriate leadership development programs.

An example of how we may target leadership development based on gender can be drawn from the work on modesty discussed in this paper. Based on the finding that women who are modest are more likely to suffer in terms of remuneration and career progression, leadership development programs for women could include training in self-promotion. The training would need to specifically address the socialized concerns of likeability and gender appropriateness in order to assist trainees in overcoming persistent and ingrained social barriers. Women need to understand that it is necessary to make one's accomplishments known to the decision makers. This training might include discussions of strategies for sharing accomplishments as well as role-plays on how to communicate the effort and achievement involved in completing a project. An appropriate level of self-promotion ensures that successes are not overlooked.

Today, organizations favour a few specific methods for developing managers. These include MBA programs, leadership training, special assignments, and coaching (Latham and Wexley, 2002). While there is the potential for variation and individual focus in some of these methods (e.g. coaching), formal leadership development programs do not address diversity in terms of their training approach. For example, culture and gender issues, in terms of leader behaviours, are not typically addressed as part of a core MBA or executive development program. There is an assumption that leaders need a similar set of general skills despite individual differences. The research described previously indicates that this is not the case.

At the beginning of the twenty-first century, women represented 30 percent of the students in MBA programs (Catalyst, 2002). In a survey of current students, women identified many obstacles to enrolling in MBA programs including a lack of female role models in classroom case examples (Catalyst, 2002). There is a real practical concern 
that current models of leadership development do not reflect the needs of potential female leaders. Continued research in the area of female leadership is needed to help to fill this gap, develop appropriate models of female leadership that are complementary to, yet distinct from current models of leadership. These models can then be used to inform our knowledge of how to develop future leaders who are women.

\section{References}

Ayman, R. (2004), "Situational and contingency approaches to leadership", in Antonakis, J., Cianciolo, A.K. and Sternberg, R.J. (Eds), The Nature of Leadership, Sage, Thousand Oaks, CA, pp. 148-70.

Bandura, A. (1986), Social Foundations of Thought and Action: A Social Cognitive Theory, Prentice-Hall, Englewood Cliffs, NJ.

Bartol, K.M. and Martin, D.C. (1986), "Women and men in task groups", in Ashmore, R.D. and Del Boca, F.K. (Eds), The Social Psychology of Female-Male Relations, Academic Press, Orlando, FL, pp. 259-310.

Beall, A.E., Eagly, A.H. and Sternberg, R.J. (2004), "Introduction", in Eagly, A.H., Beall, A.E. and Sternberg, R.J. (Eds), The Psychology of Gender, 2nd ed., Guilford Press, New York, NY, pp. 1-8.

Berg, J.H., Stephan, W.G. and Dodson, M. (1981), "Attributional modesty in women”, Psychology of Women Quarterly, Vol. 5 No. 5, pp. 711-27.

Boldry, J., Wood, W. and Kashy, D.A. (2001), "Gender stereotypes and the evaluation of men and women in military training", Journal of Social Issues, Vol. 57 No. 4, pp. 689-705.

Brescoll, V. (2007), "“When can angry women get ahead? Status conferral, gender, and workplace emotion expression", paper presented at the Annual Meeting of the Academy of Management, Philadelphia, PA.

Budworth, M. and Mann, S.L. (2007), "Modesty, gender, and income: the feminine modesty effect and income of unionized employees", paper presented at the annual meeting of the Academy of Management, Philadelphia, PA.

Catalyst (2002), 2002 Catalyst Census of Women Corporate Officers and Top Earners of Canada, available at: www.catalystwomen.org/files/fact $/ 2002 \% 20$ Canadian $\% 20 \mathrm{COTE} \% 20 \mathrm{Fact}$ $\%$ 20Sheet.pdf

Cialdini, R.B. and De Nicholas, M.E. (1989), "Self-presentation by association", Journal of Personality and Social Psychology, Vol. 57, pp. 626-31.

Daubman, K.A. and Sigall, H. (1997), "Gender differences in perceptions of how others are affected by self-disclosure of achievement", Sex Roles, Vol. 37, pp. 73-89.

Eagly, A.H. (2007), "Female leadership advantage and disadvantage: resolving the contradictions", Psychology of Women Quarterly, Vol. 31, pp. 1-12.

Eagly, A.H. and Carli, L.L. (2007), "Women and the labyrinth of leadership", Harvard Business Review, Vol. 85, pp. 62-82.

Eagly, A.H. and Karau, S.J. (2002), "Role congruity theory of prejudice toward female leaders", Psychological Review, Vol. 109 No. 3, pp. 573-98.

Eagly, A.H., Hohannesen-Schmidt, M.C. and van Engen, M.L. (2003), "Transformational, transactional, and laissez-faire leadership styles: a meta-analysis comparing women and men", Psychological Bulletin, Vol. 124 No. 4, pp. 591-6.

Eagly, A.H., Karau, S.J. and Makhijani, M.G. (1995), "Gender and the effectiveness of leaders: a meta-analysis", Psychological Bulletin, Vol. 117, pp. 125-45. 
Forret, M.L. and Dougherty, T.W. (2004), "Networking behaviours and career outcomes: differences for men and women?", Journal of Organizational Behavior, Vol. 23 No. 3, pp. 419-37.

Giacalone, R.A. and Riordan, C.A. (1990), "Effect of self-presentation on perceptions and recognition in an organization", The Journal of Psychology, Vol. 124 No. 1, pp. 25-38.

Gould, R.J. and Slone, C.G. (1982), "The 'feminine modesty effect': a self-presentational interpretation of sex differences in causal attribution", Personality and Social Psychology Bulletin, Vol. 8, pp. 477-85.

Heilman, M.E. and Chen, J.J. (2005), “Same behavior, different consequences: reactions to men's and women's altruistic citizenship behavior", Journal of Applied Psychology, Vol. 90 No. 3, pp. 431-41.

Kacmar, K.M., Carlson, D.S. and Bratton, V.K. (2004), "Situational and dispositional factors as antecedents of ingratiatory behaviors in organizational settings", Journal of Vocational Behavior, Vol. 65 No. 2, pp. 309-31.

Kacmar, K.M., Delery, J.E. and Ferris, G.R. (1992), "Differential effectiveness of applicant impression management tactics on employment interview decisions", Journal of Applied Social Psychology, Vol. 22 No. 16, pp. 1250-72.

Landau, J. (1995), "The relationship of race and gender to managers' ratings of promotion potential", Journal of Organizational Behavior, Vol. 14 No. 4, pp. 391-440.

Latham, G.P. and Wexley, K.N. (2002), Developing and Training Human Resources in Organizations, 3rd ed., Prentice-Hall, Upper Saddle River, NJ.

Rudman, L.A. (1998), "Self-promotion as a risk factor for women: the costs and benefits of counter-stereotypical impression management", Journal of Personality and Social Psychology, Vol. 74 No. 3, pp. 629-45.

Rudman, L.A. and Glick, P. (1999), "Feminized management and backlash toward agentic women: the hidden costs to women of a kinder, gentler image of middle management", Journal of Personality and Social Psychology, Vol. 77, pp. 1004-10.

Rudman, L.A. and Glick, P. (2001), "Prescriptive gender stereotypes and backlash toward agentic women", Journal of Social Issues, Vol. 57 No. 4, pp. 743-62.

Sinclair, A. (1995), "Sex and the MBA", Organization, Vol. 2 No. 2, pp. 295-317.

Sinclair, A. (1997), "The MBA through women's eyes: learning and pedagogy in management education", Management Learning, Vol. 28 No. 3, pp. 313-30.

Statistics Canada (2006), Women in Canada 2005, Product number 89-503-XPE, Statistics Canada, Ottawa.

Tannen, D. (1994), Talking from 9 to 5: How Women's and Men's Conversational Styles Affect Who Gets Heard, Who Gets Credit, and What Gets Done at Work, William Morrow and Company, New York, NY.

Wade, M.E. (2001), "Women and salary negotiation: the costs of self-advocacy", Psychology of Women Quarterly, Vol. 25 No. 1, pp. 65-76.

Yanar, B., Budworth, M. and Latham, G.P. (2008), "The effect of training in verbal self-guidance on self-efficacy and reemployment of Turkish women", Applied Psychology: An International Review, Vol. 58 No. 4, pp. 220-8.

\section{Further reading}

Davison, H.K. and Burke, M.J. (2000), "Sex discrimination in simulated employment contexts: a meta-analytic investigation", Journal of Vocational Behavior, Vol. 56, pp. 225-48. 
Heffernan, M. (2002), “The female CEO”, Fast Company, Vol. 61, August, p. 9.

Sharpe, R. (2000), "As leaders, women rule: new studies find that female managers outshine their male counterparts in almost every measure", Business Week Online, November 20, available at: www.businessweek.com/common_frames/ca.htm?/2000/00_47/b3708142.htm

Williams, C.L. (1995), Still a Man's World: Men Who Do "Women's Work", University of California Press, Berkeley, CA.

\section{About the authors}

Marie-Hélène Budworth is an Assistant Professor of Human Resource Management at York University, in Toronto, Ontario, Canada. Her research interests include training, development, and team process. Marie-Hélène Budworth is the corresponding author and can be contacted at: budworth@yorku.ca

Sara L. Mann PhD is an Assistant Professor of Human Resource Management at Guelph University, in Guelph, Ontario, Canada. Her research interests include job performance, unions, and low wageworkers. 